\title{
O CRITÉRIO DA ÁREA DE TERRAS NO ENQUADRAMENTO DO SEGURADO ESPECIAL
}

Joicemar Paulo Van Der Sand ${ }^{1}$

\section{RESUMO}

O presente artigo, por meio do método de abordagem hipotético-dedutivo, objetiva abordar a questão da área de terras na caracterização do segurado especial. O objetivo é demonstrar a consequência da modificação oriunda da Lei $\mathrm{n}^{\circ}$ 11.718/2008, que alterou a Lei de Benefícios da Previdência Social, estabelecendo o limite de terras em quatro módulos fiscais para a caracterização do segurado especial. Observa-se, com o estudo realizado, com base na pesquisa jurisprudencial, que a área de terras deve ser relativizada na caracterização do segurado especial.

Palavras-chave: Propriedade rural; área de terras; segurado especial; módulo rural; módulo fiscal

\section{THE LAND AREA CRITERIA TO THE SPECIAL INSURED ANALYSIS}

\begin{abstract}
This article, through the hypothetical-deductive approach, aims to study the land area in the characterization of the special insured. The objective is to demonstrate the consequence of the amendment from Law 11,718/2008, which modified the Social Security Benefits Law, establishing the land limit in four tax modules for the characterization of the special insured. It is observed, with the study carried out, based on the jurisprudential research, that the land area should be relativized in the characterization of the special insured.
\end{abstract}

Keywords: Rural property; land area; special insured; rural module; fiscal module

\section{INTRODUÇÃO}

O advento da Lei $n^{\circ} 11.718 / 2008$, representou algumas alterações na concessão dos benefícios previdenciários aos segurados especiais, dentre elas o enquadramento do segurado especial considerando a área de terras.

Trabalhadores rurais têm sido excluídos dos benefícios previdenciários porque a área de terras ultrapassa o limite previsto na Lei de Benefícios. Embora, exercendo a atividade rural em regime de economia familiar, o fato de superar o limite legal impede o acesso aos benefícios previdenciários.

O tamanho da propriedade é importante para o enquadramento do segurado especial,

\footnotetext{
${ }^{1}$ Advogado. Graduado em Direito pela Universidade Regional do Noroeste do Estado do Rio Grande do Sul. Pós-graduando em Direito Previdenciário e Direito do Trabalho pelo Instituto Cenecista de Ensino Superior de Santo Ângelo-RS.
} 
porem, esse critério não pode ser analisado isoladamente. O enquadramento do segurado especial deve considerar todos os aspectos relacionados à atividade rural familiar e não exclusivamente na área de terras.

Nesse contexto, buscamos analisar os aspectos da legislação relacionados ao tamanho da propriedade como instrumento de caracterização do trabalhador rural familiar, considerado segurado especial da Previdência Social.

Para compreendermos o fator da área de terras como critério de enquadramento do segurado especial é fundamental traçarmos os principais aspectos da caracterização da propriedade familiar, considerando a Constituição Federal, as principais leis civis e principalmente destacar o segurado especial de acordo com a legislação previdenciária.

Assim, no primeiro capítulo o objeto é a caracterização da propriedade rural familiar com enfoque na Constituição Federal e na legislação ordinária, tomando como base a Lei $n^{\circ}$ 4.504, denominada de Estatuto da Terra, criada em 1964 para disciplinar o uso da terra e as relações fundiárias no Brasil. Nesse estudo também é importante a diferenciação entre o módulo rural e módulo fiscal, mormente utilizado pela legislação como critério de diferenciação entre a propriedade rural familiar e patronal, inclusive, na fixação dos impostos.

Em seguida, destacamos o segurado especial na legislação previdenciária, traçando de forma sintetizada um histórico e o advento da Lei $n^{\circ} 11.718 / 2008$, cujo objetivo é entender o instrumento de alteração do conceito de segurado especial, criado com o fator do tamanho da propriedade.

Nesse contexto, finalizamos destacando a questão da área de terras, como elemento de caracterização para fins previdenciários na definição do segurado especial, numa análise comparativa entre a Constituição Federal e legislação ordinária, bem como, a inconstitucionalidade da Lei $n^{\circ}$ 11.71/2008, ao adotar critério não previsto pela Carta Magna para a caracterização do segurado especial. Por fim, considerando que o tema perpassa pela interpretação do poder judiciário, concluímos com alguns julgados dos nossos tribunais, buscando demonstrar se a área de terras deve ou não caracterizar-se como elemento definidor do direito previdenciário ao segurado especial.

\section{PRINCIPAIS ASPECTOS DA CARACTERIZAÇÃO DA PROPRIEDADE RURAL FAMILIAR}

A Constituição Federal de 1988, através do art. 195, § 8º inseriu os trabalhadores 
rurais no âmbito da Seguridade Social, destacando fundamentalmente o exercício da atividade em regime de economia familiar.

A partir daí o termo agricultura familiar passou a ter grande relevância, em inúmeras discussões, principalmente a partir da década de 1990, relaciona à questão fundiária e à diversidade de situações apresentadas pelas regiões brasileiras, propiciando um ambiente de debate, principalmente com a participação do movimento sindical e os demais órgãos vinculados ao meio rural e à agricultura de um modo geral.

Nesse contexto, a agricultura familiar é definida à partir dos aspectos que envolvem a estrita relação entre a terra, o trabalho e a família, sendo que a agricultura familiar apresenta especificidades em relação à agricultura empresarial, patronal.

A agricultura familiar caracteriza-se pelo controle da família sobre os meios de produção e ao mesmo tempo é a principal responsável pela absorção da mão-de-obra familiar. A esse respeito Lamarche (1993, p. 15), descreve que a exploração familiar corresponde

[...] a uma unidade de produção agrícola onde propriedade e trabalho estão intimamente ligados à família. A interdependência desses três fatores no funcionamento da exploração engendra necessariamente noções mais abstratas e complexas, tais como a transmissão do patrimônio e a reprodução da exploração.

Assim sendo, a propriedade familiar é conceituada, seguindo-se a definição estabelecida à partir do art. $4^{\circ}$, da Lei $n^{\circ} 4.504$, de 30 de novembro de 1964 - o Estatuto da Terra, como sendo o imóvel rural que é explorado pelo agricultor e sua família, absorvendo toda a força de trabalho e que garante a subsistência e o progresso social e econômico, eventualmente com a ajuda de terceiros, com área máxima fixada para cada região e tipo de exploração.

Nesse sentido, José Ribeiro da Silva e Paulo de Jesus, transcrevem o conceito da agricultura familiar à partir do estudo feito pelo Instituto Nacional de Colonização e Reforma Agrária - INCRA e pelo Fundo das Nações Unidas para a Agricultura e Alimentação - FAO, descrevendo que:

[...] O conceito do Dossiê Estatístico elaborado pelo Instituto Nacional de Colonização e Reforma Agrária - INCRA e o Fundo das Nações Unidas para a Agricultura e Alimentação - FAO (1996), define a Agricultura Familiar a partir de três características centrais: a) gestão da unidade produtiva e os investimentos nela realizados são feitos por indivíduos que mantém entre si laços de sangue ou de casamento; b) a maior parte do trabalho é igualmente fornecida pelos membros da família; e, c) a propriedade dos meios de produção (embora nem sempre da terra) pertence à família e é em seu interior que se realiza sua transmissão em caso de falecimento ou de aposentadoria dos responsáveis pela unidade produtiva 
Assim, a importância da agricultura familiar no processo de desenvolvimento rural é inquestionável, pois seu potencial vai além da produção de alimentos. Discute-se hoje o papel na continuidade de ocupação e renda nos espaços rurais, assim como a responsabilidade pela utilização sustentável dos recursos naturais.

Dentro dessa perspectiva, ressaltam-se os diversos fenômenos que acontecem no meio rural brasileiro. "Novos espaços surgiram, permitindo que houvesse inúmeras manifestações sobre o papel da agricultura familiar e do próprio desenvolvimento rural” (FLORES, 2002, p.347). Ainda nessa perspectiva, “[...] fortalecer a agricultura familiar como expressão social, econômica e política, significa rediscutir o modelo de desenvolvimento do mundo rural, com todos os seus impactos sobre a área urbana" (FLORES, 2002, p.347).

\subsection{CONCEITO DE PEQUENA PROPRIEDADE RURAL}

O aspecto que tem rendido muitos debates é a definição do que realmente pode ser considerada uma propriedade rural familiar, também denominada pequena propriedade rural.

A Constituição Federal de 1988, em seu artigo 5º inciso XXVI, dispõe que: “A pequena propriedade rural, assim definida em lei, desde que trabalhada pela família, não será objeto de penhora para pagamento de débitos decorrentes de sua atividade produtiva, dispondo a lei sobre os meios de financiar o seu desenvolvimento."

Nota-se que a Constituição adotou tratamento especial para a pequena propriedade, porém, não define o que é a pequena propriedade rural, deixando à mercê da lei específica, que até hoje não existe.

Nesse contexto, vem à baila algumas normas que tratam sobre a pequena propriedade rural, como por exemplo, o Decreto-Lei $n^{\circ} 1.166 / 71$, que dispõe sobre o enquadramento e contribuição sindical rural, através do art. $1^{\circ}$, inciso I e II, define as categorias econômicas do trabalhador rural e do empresário ou empregador rural, sendo que o trabalhador rural é aquele subordinado ao empregador rural como empregado e aquele que, proprietário ou não, trabalha individualmente ou com a família, cuja atividade é indispensável à subsistência, inclusive, com eventual ajuda de terceiros e o empresário ou empregador rural (pessoa física ou jurídica) é quem empreende a atividade rural com a utilização de empregados ou mesmo sem empregados, inclusive, em regime de economia familiar, explora imóvel rural de área superior a dois módulos rurais ou se mais de um imóvel, a soma das áreas ultrapassa a dois módulos rurais da região. 
Ao se estabelecer as diretrizes para a formulação da Política Nacional da Agricultura Familiar e Empreendimentos Familiares Rurais, através da Lei n ${ }^{\circ} 11.326$, de 24 de julho de 2006, novamente a definição e caracterização da pequena propriedade rural ficou nos limites dos quatro módulos fiscais, conforme disposto no art. $3^{\circ}$, definindo que:

\footnotetext{
Art. $3^{\circ}$ Para os efeitos desta Lei, considera-se agricultor familiar e empreendedor familiar rural aquele que pratica atividades no meio rural, atendendo, simultaneamente, aos seguintes requisitos:

I - não detenha, a qualquer título, área maior do que 4 (quatro) módulos fiscais;

II - utilize predominantemente mão-de-obra da própria família nas atividades econômicas do seu estabelecimento ou empreendimento;

III - tenha percentual mínimo da renda familiar originada de atividades econômicas do seu estabelecimento ou empreendimento, na forma definida pelo Poder Executivo; (Redação dada pela Lei $\mathrm{n}^{\circ} 12.512$, de 2011)

IV - dirija seu estabelecimento ou empreendimento com sua família.
}

Nesse contexto, verifica-se que o conceito do trabalhador rural é basicamente em relação ao trabalho com a sua unidade familiar, cuja soma de esforços é a fonte de subsistência e a caracterização da pequena propriedade rural no limite de quatro módulos fiscais, ou seja, adota-se a definição da pequena propriedade rural àquela que possui área compreendida até quatro módulos fiscais.

\subsection{MÓDULO RURAL X MÓDULO FISCAL}

Para contribuir no entendimento acerca do conceito da pequena propriedade rural, da caracterização da agricultura familiar e dos segurados especiais da Previdência Social, destacamos simplificadamente a diferença entre módulo rural e módulo fiscal.

O módulo rural adotado pelo Estatuto da Terra para caracterizar a diferenciação entre a propriedade familiar e o latifúndio foi regulamentado pelo Decreto $\mathrm{n}^{\mathrm{o}} 55.891$, de 31 de março de 1965, cujos critérios estão estabelecidos no art. 11, dispondo que a fixação da dimensão econômica do imóvel para cada região deve considerar a característica ecológica, os diversos tipos de exploração, a localização e acesso em relação ao mercado. Isso denota que o módulo rural é uma unidade variável, pois cada propriedade possui suas características peculiares.

Pode-se dizer que o módulo rural é a menor parcela de fracionamento da área rural, levando-se em conta critérios objetivos que permitem ao trabalhador extrair dali o seu sustento e da família, absorvendo-lhe toda a força própria do trabalho, ou seja, o tamanho do módulo rural deve considerar a produtividade e os custos de produção para cada região do 
país.

O módulo fiscal é unidade usada fundamentalmente para servir de base para o cálculo do Imposto Territorial Rural - ITR, cuja definição foi dada pela Lei $n^{\circ} 6.746$, de 10 de dezembro de 1979, que alterou os artigos 49 e 50 do Estatuto da Terra. Assim sendo, o art. 50, $\S 2^{\circ}$, do Estatuto da Terra, define que:

$\S 2^{\circ} \mathrm{O}$ módulo fiscal de cada Município, expresso em hectares, será determinado levando-se em conta os seguintes fatores:

a) o tipo de exploração predominante no Município:

I - hortifrutigranjeira;

Il - cultura permanente;

III - cultura temporária;

IV - pecuária;

V - florestal;

b) a renda obtida no tipo de exploração predominante;

c) outras explorações existentes no Município que, embora não predominantes, sejam expressivas em função da renda ou da área utilizada;

d) o conceito de "propriedade familiar", definido no item II do artigo $4^{\circ}$ desta Lei.

O mesmo conceito foi mantido pelo Decreto $\mathrm{n}^{\circ}$ 84.685, de 06 de maio de 1980, que regulamentou a Lei ${ }^{\circ}$ 6.746/79.

Além disso, importante destacar que o art. 50, parágrafo $3^{\circ}$ do Estatuto da Terra dispõe que o número de módulos fiscais do imóvel será obtido dividindo-se sua área aproveitável total pelo módulo fiscal do município, sendo que o parágrafo $4^{\circ}$ define o que não é considerada aproveitável: a área com benfeitorias, área com floresta ou mata de preservação permanente ou reflorestamento com essências nativas, área imprestável para qualquer exploração agrícola, pecuária ou florestal.

Portanto, o módulo fiscal deve ser considerado à partir da área aproveitável, ou seja, descontando-se a área ocupada com benfeitorias, mata de preservação, reflorestamento e inaproveitável, que é importante para a caracterização do segurado especial, pois significa que a quantificação do número de módulos fiscais não deve ser considerada pura e simplesmente na área total da propriedade.

A competência para a fixação das dimensões do módulo fiscal para cada município é do Instituto Nacional de Colonização e Reforma Agrária - INCRA.

\section{O SEGURADO ESPECIAL NA LEGISLAÇÃO PREVIDENCIÁRIA}

O surgimento da previdência social brasileira teve como marco o Decreto $\mathrm{n}^{\circ}$ 4.682/23, denominado Lei Eloy Chaves. A partir daí diversos instrumentos normativos se 
sucederam, regulamentando os direitos e a cobertura previdenciária no país.

Todavia, somente com o advento do Estatuto do Trabalhador Rural - Lei $\mathrm{n}^{\circ}$ 4.214/63, que criou o Fundo de Assistência e Previdência do Trabalhador Rural, o chamado FUNRURAL, é que surgiu a cobertura aos trabalhadores rurais, até então totalmente desprotegidos e excluídos.

A professora Jane Lucia Berwanger (2013, p. 41) leciona que:

O Estatuto do Trabalhador Rural estabeleceu normas para a estipulação do contrato de trabalho, para a sua execução, entre os quais: jornada de oito horas diárias, garantia de salário mínimo (fazendo, inclusive, expressa menção à aplicação do disposto no Capítulo III do título II da CLT, que trata dessa matéria) e obrigatoriedade de assinatura em carteira profissional. Previu, também, o pagamento de horas extras não compensadas e de adicional pelo trabalho noturno.

Nesse sentido, segundo Marisa Ferreira dos Santos (2011, p. 337), o Estatuto do Trabalhador Rural elegeu como segurados obrigatórios do FUNRURAL: "os colonos ou parceiros, bem como os pequenos proprietários rurais, empreiteiros, tarefeiros e as pessoas físicas que explorassem as atividades como trabalhadores que residissem só ou com sua família em moradia fornecida pelo empregador, desde que em número inferior a cinco”.

Todavia, somente com a Constituição de 1988, os trabalhadores rurais foram reconhecidos e incluídos nos direitos previdenciários em condição de igualdade aos trabalhadores urbanos, na forma do art. 194, parágrafo único, II, o qual garantiu a uniformidade e equivalência dos benefícios e serviços às populações urbanas e rurais, fato de grande relevância, conforme destaca Jane Lucia W. Berwanger (2013, p. 46-verso), afirmando que:

\footnotetext{
Verificamos, portanto, que apenas ha 24 anos os trabalhadores rurais empregados tiveram tratamento isonômico com os urbanos, 45 anos depois da Consolidação das Leis do Trabalho. Na previdência social, a Constituição determinou a inclusão, que somente se efetivou mais tarde com a legislação previdenciária. Queremos demonstrar, com isso, que os direitos sociais tardaram a chegar ao meio rural.
}

O texto constitucional estabeleceu particular atenção aos trabalhadores rurais, através do art. 195, parágrafo $8^{\circ}$, considerando o produtor, o parceiro, o meeiro, os arrendatários rurais e o pescador artesanal, incluindo os cônjuges, que exerçam a atividade em regime de economia familiar, sem empregados permanentes.

Ao analisar o segurado especial na Constituição Federal a professora Jane Lucia W. Berwanger (2013, p. 147) leciona que: "Embora a Constituição não tenha denominado o segurado especial, contribuiu com os principais elementos para o conceito com o qual a lei 
veio a instituí-lo como segurado da Previdência Social. Assim, não deixou totalmente a critério do legislador infraconstitucional conceituar segurado especial.”

A caracterização do segurado especial na Lei ${ }^{\circ} 8.212 / 91$, originalmente definida no inciso VII, do art. 12, dispunha que:

Art. 12. São segurados obrigatórios da Previdência Social as seguintes pessoas físicas:

VII - como segurado especial: o produtor, o parceiro, o meeiro e o arrendatário rurais, o pescador artesanal e o assemelhado, que exerçam essas atividades individualmente ou em regime de economia familiar, ainda que com auxílio eventual de terceiros, bem como seus respectivos cônjuges ou companheiros e filhos maiores de quatorze anos ou a eles equiparados, desde que trabalhem, comprovadamente, com o grupo familiar respectivo. (Redação dada pela Lei nº 8.398, de 1992).

Portanto, a Lei de Custeio da Previdência Social em nenhum momento limitou a área de terras para conceituar o segurado especial, mas somente o exercício da atividade individualmente ou em regime de economia familiar, em consonância com o que foi previsto pela Constituição de 1988.

Tanto é verdade, que a inscrição do segurado especial perante a Previdência Social ocorre através do cadastro no INSS, cujo artigo 17 , parágrafo $4^{\circ}$, da Lei ${ }^{\circ} 8.213 / 91$, assevera que:

\footnotetext{
$\S 40$ A inscrição do segurado especial será feita de forma a vinculá-lo ao seu respectivo grupo familiar e conterá, além das informações pessoais, a identificação da propriedade em que desenvolve a atividade e a que título, se nela reside ou o Município onde reside e, quando for o caso, a identificação e inscrição da pessoa responsável pela unidade familiar. (Incluído Lei $n^{\circ} 11.718$, de 2008)
}

Assim sendo, o Regulamento da Previdência Social define o regime de economia familiar como sendo a atividade rural em que o trabalho dos membros da família é indispensável à subsistência e o desenvolvimento do núcleo familiar, cuja atividade é exercida em condições de mútua dependência e colaboração.

Percebe-se assim, que a caracterização do segurado especial sempre foi o exercício da atividade rural, principalmente o regime de economia familiar, não havendo maior preocupação em relação à área de terras.

\subsection{O ADVENTO DA LEI No $11.718 / 2008$.}

Sem menosprezar as diversas alterações legislativas que se sucederam, bem como, considerando o objetivo do presente trabalho em limitar-se na análise da questão do tamanho 
da propriedade na caracterização do segurado especial, entendemos importante destacar alguns aspectos das alterações oriundas da Lei $\mathrm{n}^{\circ} 11.718$, de 20 de junho de 2008, que alterou alguns dispositivos das Leis de Custeio e de Benefícios da Previdência Social.

Com o advento da Lei $n^{\circ} 11.718 / 2008$, o art. 11, parágrafo $9^{\circ}$, da Lei $n^{\circ} 8.213 / 91$ passou a seguinte redação:

\footnotetext{
$\S 9^{\circ}$ Não é segurado especial o membro de grupo familiar que possuir outra fonte de rendimento, exceto se decorrente de:

I - benefício de pensão por morte, auxílio-acidente ou auxílio-reclusão, cujo valor não supere o do menor benefício de prestação continuada da previdência social;

II - benefício previdenciário pela participação em plano de previdência complementar instituído nos termos do inciso III do $§ 18$ deste artigo;

III - exercício de atividade remunerada em período não superior a 120 (cento e vinte) dias, corridos ou intercalados, no ano civil, observado o disposto no $§ 13$ do art. 12 da Lei no 8.212 , de 24 de julho de 1991;

IV - exercício de mandato eletivo de dirigente sindical de organização da categoria de trabalhadores rurais;

$\mathrm{V}$ - exercício de mandato de vereador do Município em que desenvolve a atividade rural ou de dirigente de cooperativa rural constituída, exclusivamente, por segurados especiais, observado o disposto no $§ 13$ do art. 12 da Lei $n^{\circ} 8.212$, de 24 de julho de 1991;

VI - parceria ou meação outorgada na forma e condições estabelecidas no inciso I do $\S 8^{\circ}$ deste artigo;

VII - atividade artesanal desenvolvida com matéria-prima produzida pelo respectivo grupo familiar, podendo ser utilizada matéria-prima de outra origem, desde que a renda mensal obtida na atividade não exceda ao menor benefício de prestação continuada da previdência social; e

VIII - atividade artística, desde que em valor mensal inferior ao menor benefício de prestação continuada da previdência social.
}

Nesse contexto, um dos aspectos é a questão da descaracterização da condição de segurado especial do membro familiar que possui outra fonte de renda. Percebe-se um abrandamento em relação ao segurado especial, com a possibilidade de vir a prestar ou contratar serviços de natureza urbana em até 120 (cento e vinte) dias por ano, o recebimento de remuneração pelo exercício de mandato sindical da categoria, salário de vereador, de dirigente de cooperativa, desde que, constituída somente por segurados especiais, bem como, na condição de que em todos os cargos haja o recolhimento da contribuição devida.

Além disso, a Lei $\mathrm{n}^{\mathrm{o}}$ 11.718/2008 disciplinou a possibilidade, pelo segurado especial, de realizar a atividade artesanal, com a aquisição de matéria-prima de terceiros, desde que a renda não seja maior que um salário mínimo mensal; a exploração da atividade turística, com hospedagem na propriedade até 120 (cento e vinte) dias por ano e até a atividade artística praticada por segurado especial, também limitada a renda mensal do salário mínimo, isto é, correspondente ao menor benefício de prestação continuada da Previdência Social.

Todas estas atividades por não estarem definidas na legislação previdenciária eram 
motivos para a descaracterização do segurado especial.

Outro aspecto, exatamente o objetivo deste artigo, é o exercício da atividade agropecuária em área de até quatro módulos fiscais, incluído pelo item 1, da alínea "a", do inciso VII, do art. 11, da Lei ${ }^{\circ}$ 8.213/91, cuja atividade e limitação não existia na Lei de Benefícios da Previdência Social.

Vimos que a definição do segurado especial sempre se limitou no exercício da atividade rural de forma individual ou em regime de economia familiar, ou seja, a lei não mencionava ou fazia distinção da atividade pecuária, situação que também foi solucionada com a alteração do inciso VII, do art. 12, da Lei no 8.212/91.

Diante disso, novamente importante destacar as lições da professora Jane Lucia W. Berwanger (2013, p. 165) afirmando que:

\begin{abstract}
Quando a lei diz "explore atividade agropecuária", entendemos que está se referindo ao efetivo exercício da atividade. Ou seja, somente vai ser segurado aquele trabalhador na terra. (...) A Constituição Federal refere produtor, parceiro, meeiro e arrendatário rurais. $\mathrm{O}$ termo agropecuária, constante na lei, se equivale ao termo rurais, na Constituição. A produção rural é agropecuária englobando as atividades agrícola (produção vegetal) e pecuária (produção animal).
\end{abstract}

Esse entendimento é vislumbrado no art. $25, \S 3^{\circ}$ da Lei $n^{\circ} 8.212 / 91$ que trata da contribuição do empregador rural e do segurado especial para fins previdenciários, definindo que:

$\S 3^{\circ}$ Integram a produção, para os efeitos deste artigo, os produtos de origem animal
ou vegetal, em estado natural ou submetidos a processos de beneficiamento ou
industrialização rudimentar, assim compreendidos, entre outros, os processos de
lavagem, limpeza, descaroçamento, pilagem, descascamento, lenhamento,
pasteurização, resfriamento, secagem, fermentação, embalagem, cristalização,
fundição, carvoejamento, cozimento, destilação, moagem, torrefação, bem como os
subprodutos e os resíduos obtidos através desses processos. (Incluído pela Lei n
o.540, de 22.12.92)

Denota-se, portanto, que a produção agropecuária é aquela exercida pelos produtores, que abrange o cultivo da produção agrícola e a criação de animais, ou seja, a produção vegetal e animal.

\title{
3 O CONTEXTO DO TAMANHO DA PROPRIEDADE PARA A CARACTERIZAÇÃO DO TRABALHADOR RURAL - SEGURADO ESPECIAL.
}

O problema fundamental é a definição do que realmente pode ser considerada uma 
propriedade rural familiar, diante da limitação da lei com base na área de terras.

Vimos que a Constituição Federal de 1988, em seu artigo $5^{\circ}$, XXVI, limitou-se no exercício da atividade rural pela família como elemento caracterizador da pequena propriedade rural, deixando a definição à mercê de lei específica.

Porém, no Direito Agrário, o Estatuto da Terra (Lei 4.504/64) em seu art. $4^{\circ}$, inciso II, conceitua que:

II - "Propriedade Familiar", o imóvel rural que, direta e pessoalmente explorado pelo agricultor e sua família, lhes absorva toda a força de trabalho, garantindo-lhes a subsistência e o progresso social e econômico, com área máxima fixada para cada região e tipo de exploração, e eventualmente trabalho com a ajuda de terceiros;

Portanto, a Constituição de 1988 basicamente recepcionou o conceito do Estatuto da Terra, sendo que até então não existia uma preocupação taxativa com relação à área de terras. $\mathrm{O}$ aspecto principal era a exploração da propriedade pelo agricultor e sua família com a absorção de toda a força de trabalho e como fonte de manutenção e subsistência.

Sobre essa limitação da área de terras para a caracterização do segurado especial na legislação previdenciária, a professora Jane Lucia W. Berwanger (2013, p 168) leciona que:

O Anexo do Decreto 3.048/99 previa a limitação de área apenas para o parceirooutorgante que cedesse parte de sua área para o parceiro-outorgado. Porem, esse dispositivo não encontrava amparo na lei, pois esta nada referia. Podemos afirmar, assim, que foi somente com a Lei 11.718//08 que se pode cogitar do limite de área ser explorada pelo segurado especial: 4 (quatro) módulos fiscais.

Constata-se, como mencionado, que a limitação da propriedade familiar em quatro módulos fiscais para caracterizar o segurado especial, somente materializou-se na Lei de Benefícios através da Lei no 11.718/2008.

Assim sendo, o art. 12, inciso VII, da Lei n ${ }^{\circ} 8.212 / 91$, passou a seguinte redação:

VII - como segurado especial: a pessoa física residente no imóvel rural ou em aglomerado urbano ou rural próximo a ele que, individualmente ou em regime de economia familiar, ainda que com o auxílio eventual de terceiros a título de mútua colaboração, na condição de:

a) produtor, seja proprietário, usufrutuário, possuidor, assentado, parceiro ou meeiro outorgados, comodatário ou arrendatário rurais, que explore atividade:

1. agropecuária em área de até 4 (quatro) módulos fiscais; ou

2. de seringueiro ou extrativista vegetal que exerça suas atividades nos termos do inciso XII do caput do art. $2 \underline{\mathrm{O}}$ da Lei no-9.985, de 18 de julho de 2000 , e faça dessas atividades o principal meio de vida;

b) pescador artesanal ou a este assemelhado, que faça da pesca profissão habitual ou principal meio de vida; e

c) cônjuge ou companheiro, bem como filho maior de 16 (dezesseis) anos de idade ou a este equiparado, do segurado de que tratam as alíneas $a$ e $b$ deste inciso, que, comprovadamente, trabalhem com o grupo familiar respectivo. 
Percebe-se que a legislação previdenciária também adotou os parâmetros já utilizados pelo Estatuto da Terra, bem como, outras leis que igualmente usam o módulo fiscal para definir a pequena propriedade rural ou familiar, como por exemplo, a Lei $\mathrm{n}^{\circ} 11.326$, de 24 de julho de 2006, que estabelece as diretrizes para a formulação da Política Nacional da Agricultura Familiar e Empreendimentos Familiares Rurais, cujo artigo $3^{\circ}$, define que:

\footnotetext{
Art. $3^{\circ}$. Para os efeitos desta Lei, considera-se agricultor familiar e empreendedor familiar rural aquele que pratica atividades no meio rural, atendendo, simultaneamente, aos seguintes requisitos:

I - não detenha, a qualquer título, área maior do que 4 (quatro) módulos fiscais;

II - utilize predominantemente mão-de-obra da própria família nas atividades econômicas do seu estabelecimento ou empreendimento;

III - tenha renda familiar predominantemente originada de atividades econômicas vinculadas ao próprio estabelecimento ou empreendimento;

IV - tenha percentual mínimo da renda familiar originada de atividades econômicas do seu estabelecimento ou empreendimento na forma definida pelo Poder Executivo; (Redação dada pela Lei 12.512/2011).

$\mathrm{V}$ - dirija seu estabelecimento ou empreendimento com sua família.
}

Também o novo Código Florestal - Lei 12.651, de 25 de maio de 2012, ao definir a pequena propriedade ou posse familiar, adotou a mesma definição, no art. $3^{\circ}$, inciso V, dispondo que:

Art. $3^{\circ}$ Para os efeitos desta Lei, entende-se por:

$\mathrm{V}$ - pequena propriedade ou posse rural familiar: aquela explorada mediante o trabalho pessoal do agricultor familiar e empreendedor familiar rural, incluindo os assentamentos e projetos de reforma agrária, e que atenda ao disposto no art. $3^{\circ}$ da Lei no 11.326 , de 24 de julho de 2006;

Ou seja, o novo Código Florestal também define a pequena propriedade familiar rural utilizando o critério da limitação de 4 (quatro) módulos fiscais.

A questão é relevante, pois considerando os dados constantes no sítio do Instituto Brasileiro de Geografia e Estatística - IBGE, tomando como exemplo o Estado do Rio Grande do Sul, composto por 497 (quatrocentos e noventa e sete) municípios, deste total 423 (quatrocentos e vinte e três) municípios possuem o módulo fiscal definido na área de 20,0 (vinte) hectares, ou seja, o limite de 4,0 (quatro) módulos fiscais é de 80,0 (oitenta) hectares, o que representa $85 \%$ (oitenta e cinco por cento) dos municípios do Estado.

Analisando o resultado do censo agropecuário do ano de 2006, disponibilizados no site do IBGE, o Estado do Rio Grande do Sul possui em torno de 441.472 unidades de estabelecimentos agropecuários, dos quais 25.380 estabelecimentos possuem de 50 
(cinqüenta) a menos de 100 (cem) hectares, ou seja, 5,7\% das propriedades. Todavia, considerando o total de propriedades com mais de zero hectare a menos de 100 hectares o total é de 404.192 unidades agropecuárias, o que representa o percentual de, 91,5\% das propriedades do Estado.

Nesse diapasão, necessário destacar o fato da área efetivamente explorada para a atividade rural, ou seja, área que caracteriza a atuação da mão-de-obra familiar, pois a maioria das propriedades é composta com área de preservação permanente, terras inaproveitáveis, aclives, etc. Explica-se: diversas áreas ultrapassam o limite de 4,0 módulos fiscais, porém descontando-se as áreas de preservação permanente, área inaproveitável, etc. resulta numa a área efetivamente cultivada que não atinge este patamar.

Vimos que o art. 50, da Lei $\mathrm{n}^{\circ}$ 4.504/64, define que o número de módulos fiscais do imóvel é obtido através da divisão da área aproveitável pelo módulo fiscal do município, desconsiderando-se área inaproveitável e de preservação, inclusive, que o imposto poderá sofrer redução de até $90 \%$ (noventa por cento) segundo o grau de utilização econômica do imóvel, ou seja, o próprio Estatuto da Terra já levou em consideração a aproveitamento do imóvel para fins da cobrança do imposto, fato que também deve ser adotado para fins do enquadramento previdenciário.

Nesse contexto, uma interpretação na "fria letra da lei" pode fazer com que numa análise de concessão de benefício previdenciário, um trabalhador rural que possuir mais de quatro módulos fiscais, embora de fato, a atividade rural seja realizada em área inferior a esse limite, seja descaracterizado desta condição e negado o seu direito previdenciário.

\subsection{A (IN)CONSTITUCIONALIDADE DA LEI.}

Partindo da premissa de que a Constituição Federal não fez nenhuma limitação na caracterização do trabalhador rural pelo tamanho da propriedade, dando ênfase a questão do trabalho e da família, ou seja, a absorção da mão-de-obra familiar na propriedade, vem a baila a inconstitucionalidade da Lei $\mathrm{n}^{\mathrm{o}} 11.718 / 2008$.

Nesse sentido, a professora Jane Lucia W. Berwanger (2013, p. 170) afirma que:

A Constituição Federal, ao tratar do segurado especial (embora essa denominação tenha sido dada pela legislação ordinária), exige que a atividade deva ser exercida em regime de economia familiar. Por sua vez, encontramos o conceito de regime de economia familiar na legislação infraconstitucional. Todavia entendemos que o elemento utilizado pela Constituição é a forma de trabalho - regime de economia familiar - e não a área de terras, ou seja, a extensão da propriedade explorada. Assim ao introduzir elemento novo, é inconstitucional a limitação da área em 4 (quatro) 
módulos fiscais, porque o elemento do conceito jurídico foi enxertado pela legislação ordinária, diverso do elemento expresso no texto constitucional.

Esse aspecto é importante, pois altera o conceito de segurado especial a partir de elementos não estabelecidos constitucionalmente, em detrimento do conceito e da caracterização estabelecida anteriormente, como leciona a professora Jane Lucia W. Berwanger (2013, p. 170):

\begin{abstract}
A inconstitucionalidade que aqui referimos está em utilizar-se de elementos estranhos, não previstos constitucionalmente, para reduzir o conceito. Não se trata de regulamentar, mas de inovar, criando condições diversas daquelas expressas na Carta Maior. O texto constitucional trata da forma de trabalho: regime de economia familiar, sem empregados permanentes. A quantidade de área explorada nada diz quanto à forma de trabalho, por isso esse critério não deve se sustentar se confrontando com a Constituição, especialmente quando se trata do valor social do trabalho. A rigor, nada difere de fato, o trabalho efetuado em área inferior ou superior quatro módulos.
\end{abstract}

Constata-se, portanto, que a limitação da área de quatro módulos fiscais para caracterizar o segurado especial, oriunda através da edição da Lei n ${ }^{\circ} 11.718 / 2008$, denota modificação em prejuízo ao que foi estabelecido pela Carta Maior, o que implica na inconstitucionalidade dos critérios utilizados pela norma infraconstitucional.

\title{
3.2 A INTERPRETAÇÃO DO PODER JUDICIÁRIO
}

Considerando essa nova situação criada com as alterações introduzidas com a publicação da Lei $n^{\circ} 11.718 / 2008$, cujo objetivo deste breve trabalho, é justamente analisar uma delas, a área de terras na caracterização do direito do segurado especial, necessário apontar alguns entendimentos no âmbito do judiciário, pois é nele que a discussão ganha os contornos do entendimento.

Nesse contexto, a pesquisa nos Tribunais indica que há decisões judiciais que aplicaram retroativamente a limitação da área, como por exemplo, na Apelação Cível $n^{\circ}$ 0003601-70.2010.4.03.6005, do TRF da $3^{\text {a }}$ Região, $7^{\text {a }}$ Turma, Relator Desembargador Federal Fausto de Sanctis, julgamento em 12 de novembro de 2012:

PROCESSUAL CIVIL. AGRAVO. ARTIGO 557, § $1^{\circ}$, DO CÓDIGO DE PROCESSO CIVIL. AÇÃO DE APOSENTADORIA RURAL POR IDADE. PROVA MATERIAL. PROPRIEDADE COM 5 MÓDULOS FISCAIS. AFASTADO O TRABALHO EM REGIME DE ECONOMIA FAMILIAR. 1- O fato de a autora possuir uma propriedade com 05 módulos fiscais (fl. 102) e havendo prova documental de que naquele local foram comercializadas, a título 
exemplificativo, 33 toneladas de soja no ano de 1995, 39 toneladas, em 1996, e, assim, sucessivamente, até o ano de 2008 (fls. 20/33), não há como inseri-la na condição de segurada especial que explore a atividade em regime de economia familiar. 2- Agravo a que se nega provimento.

No mesmo sentido, a Apelação Cível no 0006697-71.2010.4.01.9199, do TRF da $1^{\text {a }}$ Região, $1^{\text {a }}$ Turma, Relator Desembargador Federal Kassio Nunes Marques, publicado no Diário Eletrônico da Justiça Federal em 20 de fevereiro de 2013:

\begin{abstract}
APELAÇÃO CÍVEL. PREVIDENCIÁRIO. APOSENTADORIA RURAL POR IDADE. PROVA DOCUMENTAL. IMÓVEL RURAL COM ÁREA SUPERIOR A 04 (QUATRO) MÓDULOS FISCAIS. DEPOIMENTO TESTEMUNHAL. SÚMULAS 149/STJ e 27/TRF-1 ${ }^{\mathrm{a}}$ REGIÃO. REQUISITOS LEGAIS NÃO PREENCHIDOS. CONCESSÃO INDEVIDA. 1. Não restou comprovado o efetivo exercício de atividade rural, na condição de segurado especial, em regime de economia familiar, vez ser a parte autora proprietária de mais de um imóvel rural, ou seja, não se enquadrando na definição de segurado especial, nos termos do art. 11, VII, a, 1, da Lei 8213/91, que o define como aquele que exerce atividade agropecuária, em regime de economia familiar. 2. A produção de prova exclusivamente testemunhal é insuficiente à comprovação da atividade rurícola para efeito da obtenção de benefício previdenciário, nos termos das Súmulas 149 do STJ e 27 deste Tribunal. 3. A parte autora não faz jus ao benefício de aposentadoria rural por idade, previsto nos arts. 143 e 11, VII, ambos da Lei 8.213/91, porquanto as provas documentais produzidas nos autos não foram suficientes para demonstrar a sua condição de rurícola. 4. Apelação a que se nega provimento.
\end{abstract}

Note-se que as apelações tratam de processos ajuizados em 2010, onde o período da atividade rural é praticamente todo anterior ao advento da Lei $n^{\circ} 11.718 / 08$, ou seja, a decisão prolatada em 2012 analisou todo o período considerando a lei nova, pois o fato do segurado possuir mais de quatro módulos fiscais - a limitação de área não descaracterizava sua condição antes do advento desta Lei.

A professora Jane Lucia W. Berwanger (2013, p. 172) afirma que:

Há flagrante afronta dessas decisões ao princípio da irretroatividade da norma tributária, pois para que o produtor com mais de quatro módulos pudesse computar o período de carência teria que comprovar a contribuição como contribuinte individual do período retroativo, de um período em que a lei o enquadrava como segurado especial, e não como contribuinte individual.

A professora também assevera que face à inexistência de norma legal nesse sentido nos períodos anteriores ao advento da Lei $\mathrm{n}^{\mathrm{o}} 11.718 / 08$, tais decisões ofendem ao princípio da legalidade, bem como, à segurança jurídica, tão valorizada no denominado Estado Democrático de Direito, entendendo que, em nenhuma hipótese, deve-se cogitar a aplicação desta lei para os benefícios requeridos naquele período.

Em relação a irretroatividade da Lei $n^{0}$ 11.718/08 encontramos decisões nos 
Tribunais Regionais Federais, dentre as quais os Embargos de Declaração em Apelação Cível $\mathrm{n}^{\mathrm{o}}$ 0003265-05.2006.4.01.3308, do TRF da $1^{\mathrm{a}}$ Região, $2^{\mathrm{a}}$ Turma, Relator Desembargador Federal Francisco de Assis Betti, publicado no Diário Eletrônico da Justiça Federal em 27 de setembro de 2013:

\begin{abstract}
PROCESSUAL CIVIL. EMBARGOS DE DECLARAÇÃO. OMISSÃO CONFIGURADA. RECEBIMENTO DE PENSÃO DE EMPRESÁRIO RURAL. MÓDULOS FISCAIS. CONDIÇÃO DE RURÍCOLA NÃO DESCARACTERIZADA. EMBARGOS PARCIALMENTE ACOLHIDOS. SEM ALTERAÇÃO NO RESULTADO DO JULGAMENTO. 1. Uma das funções a que se destinam os embargos de declaração é resolver omissão porventura existente no julgado, a teor do art. 535, inc. II, do Código de Processo Civil. 2. O Acórdão não pronunciou quanto à alegação de descaracterização da condição de rurícola em razão do recebimento de pensão por morte de empresário rural, bem como em razão do tamanho do imóvel rural. 3. O fato de autora receber pensão por morte "empregador rural" não descaracteriza sua condição de segurada especial, pois, em virtude das disposições do Decreto-lei 1.166/71, a qualificação de empregador II-B é uma referência a quem, proprietário ou não, mesmo sem empregado, em regime de economia familiar, explore imóvel rural que lhe absorva toda a força de trabalho e lhe garanta a subsistência, em área não superior a dois módulos rurais da respectiva região. 4. A extensão do imóvel rural da requerente não é superior ao limite de 04 módulos fiscais (art. 11, V, a da Lei 8.213/91), e, ainda que fosse, não prejudicaria a pretensão, mormente porque a autora já havia implementado os requisitos legais desde 1991, anterior ao advento da Lei 11.718/2008 que acrescentou a referida restrição. 5. Embargos de declaração parcialmente acolhidos (itens 3 e 4), sem alteração, contudo, da conclusão do julgamento embargado. (grifo nosso)
\end{abstract}

Na mesma linha, a Apelação em Reexame Necessário no 0012079-47.2014.404.9999,

do TRF da $4^{\text {a }}$ Região, $5^{\text {a }}$ Turma, Relator Desembargador Federal Ricardo Teixeira do Valle

Pereira, publicado no Diário Eletrônico da Justiça Federal em 19 de setembro de 2014:

PREVIDENCIÁRIO. LABOR RURAL EM REGIME DE ECONOMIA FAMILIAR COMPROVADO. MÓDULO FISCAL. DIREITO ADQUIRIDO ANTES DA LEI 11.718/08. APOSENTADORIA POR TEMPO DE SERVIÇO/CONTRIBUIÇÃO. REQUISITOS PREENCHIDOS. CONCESSÃO. 1. O tempo de serviço rural pode ser comprovado mediante a produção de prova material suficiente, ainda que inicial, complementada por prova testemunhal idônea. 2. Os documentos em nome de terceiros (pais/cônjuge) consubstanciam início de prova material do trabalho rural desenvolvido em regime de economia familiar. De outra parte, afigura-se possível o reconhecimento de atividade rural para fins previdenciários a partir dos 12 anos de idade. 3. Preenchidos todos os requisitos

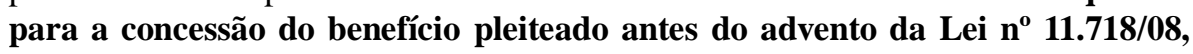
que dentre outras alterações, limitou a extensão da propriedade a quatro módulos fiscais, não pode a parte autora ser prejudicada pela introdução desse novo requisito para fins de configuração da condição de segurado especial, sob pena de ofensa ao direito adquirido. De anotar, ainda, que as Turmas de Previdenciário desta Corte, antes da referida inovação trazida pela Lei 11.718/08, adotavam o entendimento de que a extensão da propriedade não descaracterizava, por si só, a condição de segurado especial, pois deveria ser analisada juntamente com o restante do conjunto probatório. 4. Comprovado o exercício de atividades rurais, as quais devem ser acrescidas ao tempo reconhecido 
pelo INSS, tem o segurado direito à concessão do benefício de aposentadoria por tempo de serviço/contribuição nas condições que lhe sejam mais favoráveis, em respeito ao direito adquirido e às regras de transição, tudo nos termos dos artigos $5^{\circ}$, inciso XXXVI, da CF, $3^{\circ}$ e $9^{\circ}$ da EC 20/98 e $3^{\circ}$ e $6^{\circ}$ da Lei 9.876/99. (idem)

Todavia, há inúmeras decisões, principalmente no âmbito do Tribunal Regional Federal da $4^{\mathrm{a}}$ Região, como a Apelação em Reexame Necessário $\mathrm{n}^{\mathrm{o}}$ 001388498.2015.404.9999, 6 a $^{\mathrm{a}}$ Turma, Relator João Batista Pinto Silveira, publicado no Diário Eletrônico da Justiça Federal em 24 de novembro de 2015, cujo entendimento é no sentido de que o fato da propriedade ser superior a quatro módulos rurais não descaracteriza por si só o regime de economia familiar, vejamos:

EMENTA: PREVIDENCIÁRIO. APOSENTADORIA POR IDADE
RURAL. ATIVIDADE RURAL EM REGIME DE ECONOMIA FAMILIAR.
INÍCIO DE PROVA MATERIAL CORROBORADO PELA PROVA
TESTEMUNHAL. EXTENSÃO DA PROPRIEDADE RURAL. REQUISITOS
PREENCHIDOS. CONCESSÃO DO BENEFÍCIO. TUTELA ESPECÍFICA. 1. O
tempo de serviço rural para fins previdenciários pode ser demonstrado através de
início de prova material suficiente, desde que complementado por prova testemunhal
idônea. 2. A extensão da propriedade não constitui óbice, por si só, ao
reconhecimento da condição de segurado especial, devendo ser analisada
juntamente com o restante do conjunto probatório que, na hipótese,
confirmou o exercício de somente atividade rural pelo grupo familiar. 3 .
Restando comprovado nos autos o requisito etário e o exercí́cio de atividade rural no
período de carência, é de ser concedida a aposentadoria por idade rural à parte autora
a contar do requerimento administrativo, a teor do disposto no art. 49, II, da Lei no
8.213/91. 4. Determina-se o cumprimento imediato do acórdão naquilo que se refere
à obrigação de implementar o benefício, por se tratar de decisão de eficácia
mandamental que deverá ser efetivada mediante as atividades de cumprimento da
sentença stricto sensu previstas no art. 461 do CPC, sem a necessidade de um
processo executivo autônomo (sine intervallo). (grifamos)

Decisão idêntica, na Apelação em Reexame Necessário n no 001581658.2014.404.9999, do TRF da $4^{\text {a }}$ Região, 5 $5^{\text {a }}$ Turma, Relator Taís Schilling Ferraz, publicado no Diário Eletrônico da Justiça Federal em 12 de agosto de 2015.

Denota-se, portanto, que a área da propriedade deve ser sopesada com temperamento para a análise da caracterização do segurado especial, pois apesar da limitação introduzida com o advento da Lei $\mathrm{n}^{\mathrm{o}} 11.718 / 08$, evidencia-se que a principal condição ainda é o exercício da atividade rural com a família, absorvendo a força produtiva e dali tirando o sustento.

Tanto é verdade, que antes da alteração introduzida pela Lei ${ }^{\circ} 11.718 / 08$, a questão do módulo de terras na caracterização do segurado especial já era objeto de discussão judicial, sendo que a Turma Nacional de Uniformização dos Juizados Especiais Federais - TNU, publicou em 13 de fevereiro de 2006, a Súmula 30, definindo que: "Tratando-se de demanda previdenciária, o fato de o imóvel ser superior ao módulo rural não afasta, por si só, a 
qualificação de seu proprietário como segurado especial, desde que comprovada, nos autos, a sua exploração em regime de economia familiar.”

\section{CONCLUSÃO}

O trabalhador rural familiar, considerado segurado especial da previdência, efetivamente teve os seus direitos previdenciários efetivados à partir da Constituição de 1988, cuja regularização veio em 1991, com as leis de custeio e de benefícios.

Até o advento da Lei $n^{\circ} 11.718 / 2008$, não havia o critério da área de terras como fator de caracterização do segurado especial, cujo enquadramento se dava basicamente pelo efetivo exercício da atividade rural em regime de economia familiar, mediante a utilização da mãode-obra e força de trabalho com mútua dependência entre os membros da família e o aproveitamento da propriedade.

A adoção do limite de quatro módulos fiscais para a definição do enquadramento do segurado especial resulta inovação das condições expressas na Carta Maior, que trata da forma de trabalho: regime de economia familiar, sem empregados permanentes. A quantidade de área explorada nada tem a ver com a forma de trabalho, por isso esse critério não deve prevalecer.

Denota-se que a inclusão do limite da área de terras de até 4,0 módulos fiscais para caracterizar o segurado especial, nada mais é do que acrescentar na legislação previdenciária aquele limite que outras leis ordinárias já disciplinaram no tratamento do trabalhador rural, como por exemplo, o Estatuto da Terra.

Todavia, considerando que a lei $\mathrm{n}^{\mathrm{o}}$ 11.718/2008 estabeleceu o limite através do módulo fiscal não pode passar desapercebido que o Estatuto da Terra já define que o módulo fiscal é obtido à partir de divisão da área aproveitável total pelo módulo fiscal do município, bem como, que não é considerada aproveitável a área com benfeitorias, área com floresta ou mata de preservação permanente ou reflorestamento com essências nativas, área imprestável para qualquer exploração agrícola, pecuária ou florestal.

Portanto, a interpretação do limite de quatro módulos fiscais pela legislação previdenciária não pode pura e simplesmente ser baseada na soma da área total da propriedade do trabalhador rural - segurado especial. Cabe ao INSS apurar o número de módulos fiscais à partir do conceito e dos critérios estabelecidos pela legislação, sob pena de resultar na exclusão do direito aos benefícios previdenciários dos segurados especiais. 
Além disso, vimos que a jurisprudência já vem confirmando que o critério da área de terras não pode ser analisado isoladamente. O enquadramento do segurado especial deve considerar todos os aspectos definidos em lei, desde a forma da atividade, a produção até a área de terras.

\section{REFERÊNCIAS}

BARROS, Wellington Pacheco Barros. Direito ambiental sistematizado. Porto Alegre. Livraria do Advogado Editora, 2008.

BERWANGER, Jane Lucia Wilhelm. Segurado especial: o conceito jurídico para além da sobrevivência individual. Curitiba: Juruá, 2013.

BRASIL. Decreto $\mathbf{n}^{\circ}$ 55.891, de 31 de março de 1965. Regulamenta o Capítulo I do Título I e a Seção III do Capítulo IV do Título II da Lei no 4.504, de 30 de novembro de 1964 Estatuto da Terra. Disponível em: <www.planalto.gov.br/ccivil_03/ decreto/19501969/D5589.htm>. Acesso em julho de 2015.

Decreto-Lei $n^{0}$ 1.166, de 15 de abril de 1971. Dispõe sobre o enquadramento e contribuição sindical rural. Disponível em: <www.planalto.gov.br/ ccivil_03/DecretoLei/1965-1988/Del1166.htm>. Acesso em julho de 2015.

Lei $\mathbf{n}^{0}$ 4.504, de 30 de novembro de 1964. Dispõe sobre o Estatuto da Terra e dá outras providências. Disponível em: <www.planalto.gov.br/ccivil_03/ Leis/L4504.htm>. Acesso em julho de 2015.

Lei $n^{\circ}$ 5.889, de 08 de junho de 1973. Estatui normas reguladoras do trabalho rural. Disponível em: <www.planalto.gov.br/ccivil_03/Leis/L5889.htm>. Acesso em julho de 2015.

Lei $\mathbf{n}^{\circ}$ 8.022, de 12 de abril de 1990. Altera o sistema de administração das receitas federais, e dá outras providências. Disponível em: <www.planalto.gov.br/ccivil_03/Leis/1989_1994/L8022.htm>. Acesso em julho de 2015.

Códigos 4 em 1 Saraiva : CLT, CPC, Legislação Previdenciária e Constituição Federal / obra coletiva de autoria da Editora Saraiva com a colaboração de Luiz Roberto Curia, Lívia Céspedes e Juliana Nicoletti. - 10. ed. - são Paulo: Saraiva, 2015.

TRIBUNAL REGIONAL FEDERAL DA 4ª REGIÃO. Jurisprudência. Disponível em <http://www.jurisprudencia.trf4.jus.br/pesquisa/pesquisa.php?tipo=1>. Acesso em julho de 2015.

. SUPERIOR TRIBUNAL DE JUSTIÇA. Jurisprudência. Disponível em: <www.stj.jus.br/SCON>. Acesso em julho de 2015.

CASTRO, Carlos Alberto Pereira de; João Batista Lazzari. Manual de direito previdenciário. São Paulo: LTr, 2002. 
FOLMANN, Melissa (coord.). Previdência nos 60 anos da Declaração de Direitos Humanos e nos 20 da Constituição Brasileira./Melissa Folmann e Suzani Andrade Ferraro (coord.)./Curitiba: Juruá, 2008.

FLORES, Murilo. Assistência técnica e agricultura familiar. In: LIMA, Dalmo Marcelo de Albuquerque; WILKINSON, John. (org.). Inovação nas tradições da agricultura familiar. Brasília: CNPq./Paralelo. 2002. p.347-360.

SAVARIS, José Antonio (coord.). Direito Previdenciário: problemas e jurisprudência. Curitiba: Alteridade Editora, 2014.

SILVA, José Ribeiro e Paulo de Jesus. Os desafios do Novo Rural e as Perspectivas da Agricultura Familiar no Brasil. Disponível em: <http://connepi.ifal.edu.br/ocs/index.php/connepi/CONNEPI2010/paper/viewFile/1407/457>. Acesso em: 29 nov. 2015.

STRAPAZZON, Luiz Carlos (org). Previdência Social: aspectos controversos. Carlos Luiz Strapazzon, Melissa Folmann, Roberto Di Benedetto (orgs.) Curitiba: Juruá, 2009. 